\title{
Monitoring asthma in children
}

\author{
Mariëlle W. Pijnenburg ${ }^{1}$, Eugenio Baraldi ${ }^{2}$, Paul L.P. Brand ${ }^{3,4}$, \\ Kai-Håkon Carlsen ${ }^{5}$, Ernst Eber ${ }^{6}$, Thomas Frischer ${ }^{7}$, Gunilla Hedlin ${ }^{8}$, \\ Neeta Kulkarni ${ }^{9}$, Christiane Lex ${ }^{10}$, Mika J. Mäkelä ${ }^{11}$, Eva Mantzouranis ${ }^{12}$, \\ Alexander Moeller ${ }^{13}$, Ian Pavord ${ }^{14}$, Giorgio Piacentini ${ }^{15}$, David Price ${ }^{16}$, \\ Bart L. Rottier ${ }^{17}$, Sejal Saglani ${ }^{18}$, Peter D. Sly ${ }^{19}$, Stanley J. Szefler ${ }^{20}$, \\ Thomy Tonia ${ }^{21}$, Steve Turner ${ }^{22}$, Edwina Wooler ${ }^{23}$ and Karin C. Lødrup Carlsen ${ }^{24,25}$
}

Affiliations: 'Dept of Paediatrics/Paediatric Respiratory Medicine, Erasmus MC - Sophia Children's Hospital, Rotterdam, The Netherlands. 'Women's and Children's Health Dept, Unit of Respiratory Medicine and Allergy, University of Padova, Padova, Italy. ${ }^{3}$ Dept of Paediatrics/Princess Amalia Children's Centre, Isala Hospital, Zwolle, The Netherlands. ${ }^{4}$ UMCG Postgraduate School of Medicine, University Medical Centre and University of Groningen, Groningen, The Netherlands. ${ }^{5}$ Dept of Paediatrics, Institute of Clinical Medicine, University of Oslo and Oslo University Hospital, Oslo, Norway. ${ }^{6}$ Respiratory and Allergic Disease Division, Dept of Paediatrics and Adolescence Medicine, Medical University of Graz, Graz, Austria. ${ }^{7}$ Dept of Paediatrics and Paediatric Surgery, Wilhelminenspital, Vienna, Austria. ${ }^{8}$ Depart of Women's and Children's Health and Centre for Allergy Research, Karolinska Institutet and Astrid Lindgren Children's Hospital, Stockholm, Sweden. ' Leicestershire Partnership Trust and Dept of Infection, Immunity and Inflammation, University of Leicester, Leicester, UK. ${ }^{10}$ Dept of Paediatric Cardiology and Intensive Care Medicine, Division of Pediatric Respiratory Medicine, University Hospital Goettingen, Goettingen, Germany. ${ }^{11}$ Skin and Allergy Hospital, Helsinki University Hospital, Helsinki, Finland. ${ }^{12}$ Dept of Paediatrics, University Hospital of Heraklion, University of Crete, Heraklion, Greece. ${ }^{13}$ Division of Respiratory Medicine, University Children's Hospital Zurich, Zurich, Switzerland. ${ }^{14}$ Dept of Respiratory Medicine, University of Oxford, Oxford, UK. ${ }^{15}$ Paediatric Section, Dept of Life and Reproduction Sciences, University of Verona, Verona, Italy. ${ }^{16}$ Dept of Primary Care Respiratory Medicine, Academic Primary Care, Division of Applied Health Sciences, University of Aberdeen, Aberdeen, UK. ${ }^{17}$ Dept of Pediatric Pulmonology and Allergology, GRIAC Research Institute, University Medical Center Groningen, University of Groningen, Groningen, The Netherlands. ${ }^{18}$ Leukocyte Biology and Respiratory Paediatrics, National Heart and Lung Institute, Imperial College London, London, UK. ${ }^{19}$ Queensland Children's Medical Research Institute, The University of Queensland, Brisbane, Australia. ${ }^{20}$ Children's Hospital Colorado and University of Colorado Denver School of Medicine, Denver, USA. ${ }^{21}$ Institute of Social and Preventive Medicine, University of Bern, Bern, Switzerland. ${ }^{22}$ Dept of Paediatrics, University of Aberdeen, Aberdeen, UK. ${ }^{23}$ Royal Alexandra Children's Hospital, Brighton, UK. ${ }^{24}$ Dept of Paediatrics, Women and Children's Division, Oslo University Hospital, Oslo, Norway. ${ }^{25}$ Dept of Paediatrics, Faculty of Medicine, University of Oslo, Oslo, Norway.

Correspondence: Mariëlle W. Pijnenburg, Dept of Paediatrics/Paediatric Respiratory Medicine, Erasmus MC - Sophia, PO Box 2060, 3000CB Rotterdam, The Netherlands. E-mail: m.pijnenburgderasmusmc.nl

ABSTRACT The goal of asthma treatment is to obtain clinical control and reduce future risks to the patient. To reach this goal in children with asthma, ongoing monitoring is essential. While all components of asthma, such as symptoms, lung function, bronchial hyperresponsiveness and inflammation, may exist in various combinations in different individuals, to date there is limited evidence on how to integrate these for optimal monitoring of children with asthma. The aims of this ERS Task Force were to describe the current practise and give an overview of the best available evidence on how to monitor children with asthma.

22 clinical and research experts reviewed the literature. A modified Delphi method and four Task Force meetings were used to reach a consensus.

This statement summarises the literature on monitoring children with asthma. Available tools for monitoring children with asthma, such as clinical tools, lung function, bronchial responsiveness and inflammatory markers, are described as are the ways in which they may be used in children with asthma. Management-related issues, comorbidities and environmental factors are summarised.

Despite considerable interest in monitoring asthma in children, for many aspects of monitoring asthma in children there is a substantial lack of evidence.

@ERSpublications

ERS statement summarising and discussing the available literature on monitoring children with asthma http://ow.ly/H01NG 


\section{Introduction}

Asthma is a chronic, heterogeneous disease with symptoms and features that include wheeze, cough (particularly at night and during exertion), dyspnoea and chest tightness, variable airways obstruction and bronchial hyperresponsiveness (BHR). The underlying chronic inflammation is often characterised by eosinophilic activity and allergic inflammation, and airways remodelling is a frequent feature of asthma, even in young children, although not in the very early stages [1-3].

The ultimate goals of asthma treatment are to achieve and maintain clinical control, reduce future risks to the patient and enable the patient to lead a life without restrictions due to the disease [1,4-7]. The concept of asthma control is central to all asthma guidelines and the level of control is defined as the extent to which features of asthma are controlled by daily therapy, for example exertional symptoms, night awakening, the use of reliever medication and the ability to carry out daily activities. The longer-term risks for the patient with poor control include asthma attacks, impaired development or accelerated decline in lung function, and side-effects of treatment. Despite the availability of effective medication, many children do not have adequately controlled asthma $[8,9]$. This has implications for quality of life (QoL) and daily physical activity, and clearly increases the burden of disease in terms of costs to the family and society. Children with asthma frequently report limitations in activities and sports (reported in $\leqslant 47 \%$ of children with asthma), nocturnal awakening due to asthma $(\leqslant 34 \%)$ and absence from school $(\leqslant 51 \%)[8,9]$.

Asthma management should be adjusted in a continuous cycle with ongoing assessment of disease control in order to obtain and maintain asthma control and a life with no or very minimal impairment. Therefore, ongoing monitoring is essential in children with asthma and ideally provides optimal asthma control at the lowest step and dose of treatment to minimise costs and reduce possible side-effects of medication [7]. Asthma control can be assessed using many indices, including symptoms, medication use or activity limitations, and more objective surrogate measures, such as lung function or inflammatory markers reflecting the underlying pathophysiologic and immunologic mechanisms involved in the disease. Aspects of the disease that are treatment responsive should receive particularly close attention.

All components relevant to the assessment of asthma control, such as frequency and severity of symptoms, changes in lung function and level of BHR and inflammation, may exist in various combinations in different individuals; however, to date there is limited evidence on how to integrate these characteristics in the optimal monitoring of children with asthma. The definition of control based on measures of inflammation (such as sputum eosinophils and the exhaled nitric oxide fraction $\left(F_{e N O}\right)$ ) is likely to differ from control based on clinical measures (like symptoms), lung function or BHR. Moreover, information regarding the occurrence of recent exacerbations and oral corticosteroid use is important and should be included in the assessment of control and future risks, although it is often unrelated to disease severity [10].

The variable and fluctuating course of asthma symptoms and objective findings throughout childhood introduce specific challenges in terms of deciding what, when, how, how often, by whom and in whom different assessment of asthma should be performed. Variability in asthma severity, clinical presentation, exacerbations, comorbidities, age, socioeconomic status, psychosocial factors and environmental exposures may influence monitoring strategies.

Ideally, monitoring asthma in children should take into account all these aspects, but there are no clear guidelines on how to integrate these in the overall assessment of an individual patient. Therefore, in 2011 the European Respiratory Society (ERS) established a Task Force with the aim of describing current practises and giving an overview of the best available evidence on how to monitor children with asthma at various ages and, ultimately, reach better asthma control in children.

This Task Force targets children with asthma treated in primary, secondary and tertiary care.

\section{Methods}

For many aspects of monitoring asthma in children there is a paucity of data. This Statement summarises the available evidence and current practises of monitoring asthma in children. It is based on a review of the literature and the clinical expertise of the Task Force members. As no formal grading of the evidence was conducted, this statement does not contain recommendations for clinical practise.

Received: May 142014 | Accepted after revision: Sept 222014

Disclosures can be found alongside the online version of this article at erj.ersjournals.com

Four supporting documents will be published in the June 2015 issue of the European Respiratory Review: introduction; symptoms, exacerbations and quality of life; lung function, bronchial responsiveness and inflammation; and management-related issues. 
The multinational Task Force was composed of 22 clinical and research experts, and members were vetted for potential conflicts of interest according to ERS procedures. Three working groups reviewed the literature on monitoring: symptoms, exacerbations and QoL (Chair P.L.P Brand); lung function, bronchial responsiveness and airways inflammation (Chair A. Moeller); and management-related issues, comorbidities and environment (Chair B.L. Rottier). This was done through identification of systematic reviews of randomised trials, published until May 2013, via Medline/PubMed, EMBASE, the Cochrane Central Register of Controlled Trials, and supplementing this with studies that added to the evidence based on monitoring asthma in children. The Task Force members selected the relevant papers themselves, irrespective of the study designs used. A modified Delphi method with two rounds and four Task Force meetings were used to reach consensus. The Chairs (M.W. Pijnenburg and K.C. Lødrup Carlsen) composed the final document, which was reviewed and approved by all co-authors.

The summary of this Task Force's work is presented in the current paper. Four separate papers that are to be published in the European Respiratory Review (ERR) will provide detailed information on the methods available for monitoring disease, factors that should be considered when deciding on their use and management-related issues, and will also describe knowledge gaps [11-14].

\section{Limitations of this Task Force}

The present Task Force did not address the diagnosis and treatment of childhood asthma, nor did it consider monitoring of acute asthma exacerbations. The Task Force exclusively considered paediatric studies.

The availability, cost and reimbursement of the costs of different monitoring tools differ substantially throughout and between countries and influence what tools can and may be used in individual patients. The cost-effectiveness of the different monitoring tools was initially considered to be part of the task, but this was soon found to be impossible due to variability within and across countries as well as the common lack of literature to support such estimates.

\section{Recommendations on monitoring in asthma guidelines}

Over the years, the treatment goal has changed from reducing disease severity and improving long-term prognosis [15] to achieving asthma control and reducing the burden of asthma and future risks to the patient [1, 4-7]. Asthma control has been defined by the National Asthma Education and Prevention Program (NAEPP) as: "the degree to which the manifestations of asthma are minimized by therapeutic intervention and the goals of therapy are met" [1]. The Global Initiative for Asthma (GINA) distinguishes between controlled, partly controlled and poorly controlled asthma (table 1) [7].

Asthma control as a pivotal concept in asthma monitoring is included in several guidelines, whereas recommendations on monitoring are largely lacking. The GINA guidelines state that monitoring is essential "to maintain control and establish the lowest step and dose of treatment to minimize cost and maximize safety" [7]. Preferably, asthma should be monitored by the healthcare physician as well as by the patient and parents themselves using simple schemes (as seen in table 1) or composite asthma scores [7]. The British Thoracic Society (BTS) guidelines recommend the assessment of asthma control through: questions on symptoms, exacerbations and school absence; checks for adherence, inhaler technique, exposures and availability of self-management plans; and measurement of height and weight annually [6].

The American NAEPP guidelines advise that patients should be instructed to monitor their asthma control in an ongoing manner, either by monitoring symptoms or peak expiratory flow (PEF), whereas healthcare providers should assess asthma control, medication technique, the written asthma action plan, adherence, and patient concerns at every patient visit as well as spirometry at least once every 1-2 years [1].

TABLE 1 Levels of asthma symptom control according to the Global Initiative for Asthma (GINA) in patients $>5$ years of age

In the past 4 weeks has the patient had

Well controlled Partly controlled

Uncontrolled

Daytime symptoms $>2$ per week? Yes/No Any night waking due to asthma? Yes/No Reliever needed ${ }^{\#}>2$ per week? Yes/No None of these $\quad$ 1-2 of these $\quad 3$ of these Any activity limitation due to asthma? Yes/No 


\section{Factors to consider when choosing monitoring tools}

Frequency of follow-up visits

Asthma is a highly variable disease and periodic adjustment of treatment is recommended by all guidelines. However, the frequency of follow-up visits is considered a matter of clinical judgement. Most Task Force members consider that the frequency of follow-up visits depends on initial evaluation of clinical severity, with the frequency increasing in proportion to asthma severity, and may be adjusted depending on response to and intensity of treatment. The consideration of the patients' and parents' training and confidence in playing a role in the monitoring of the child's asthma also determines the frequency of follow-up visits [16]. Adequate provision of self-management education might be achieved in two or more educational and instructional sessions, followed by reviews every 3-6 months thereafter. Self-management mostly consists of symptom monitoring. The evidence indicates that peak flow monitoring, home spirometry and/or monitoring $\mathrm{FeNO}$ at home do not improve asthma outcomes compared with symptom monitoring [17-19].

Most Task Force members would schedule a follow-up visit 3-6 months after any substantial change in treatment, to discuss the degree of asthma control and to evaluate whether maintenance treatment should be modified [20]. To account for seasonal influences, one might consider scheduling follow-up visits at least every 3 months, particularly in preschool children. In children with problematic severe asthma (PSA), more frequent follow-up visits (e.g. every 1-3 months) may be warranted.

Age

Obviously, age is one of the limiting factors of the tools that may be used in monitoring asthma. In infants and toddlers, the variability and severity of asthma symptoms may prompt more frequent monitoring. In children <4-6 years of age, objective measurements of asthma control, such as lung function and inflammatory markers, are more challenging and are not feasible in all countries in routine clinical care outside specialist centres. However, electronic monitoring tools that use the internet or apps may fit the interests of adolescents in particular, although documentation for their long-term effectiveness and cost-effectiveness is currently lacking [21]. Table 2 summarises the available tools for monitoring asthma based on age.

\section{Asthma severity}

Although severity may be difficult to define, in general asthma severity is defined as the difficulty in controlling asthma with treatment and the treatment step that is necessary to achieve asthma control [4]. Children with persistent symptoms and/or severe exacerbations despite high-dose treatment, especially inhaled corticosteroids (ICS), are diagnosed with PSA and may represent $\sim 5 \%$ of children with asthma and $0.5 \%$ in a general population-based cohort $[22,23]$. Clinically, it is essential to distinguish between children with PSA who present with truly severe therapy-resistant disease and those with difficult-to-treat asthma because of underlying modifiable factors such as ongoing allergen exposure, poor adherence to treatment, poor inhaler technique, smoking and comorbidities [22]. Although clear recommendations and flow charts for the assessment of PSA have been published [24], data on and guidelines for the monitoring of PSA in children are lacking. Used in isolation, monitoring with home spirometry or with sputum eosinophils did not improve asthma outcomes in children with severe asthma [18, 25].

In general, children with severe therapy-resistant asthma are treated and monitored in tertiary care centres. In children with PSA, an increase in the frequency (e.g. every 1-3 months) and intensity of monitoring is justifiable in order to achieve asthma control and prevent side-effects of high-dose ICS treatment or treatment with oral corticosteroids.

\section{Asthma phenotypes}

As the clinical presentation of asthma varies considerably through childhood, a great deal of effort has been put into trying to identify new asthma phenotypes [26, 27] or endotypes [28] for more individually targeted management. Several phenotypes of asthma have been described, based upon the time of presentation of first wheeze, the presence of allergic sensitisation, eosinophilic or non-eosinophilic inflammation [29, 30], response to treatment [31,32], asthma severity [33] and allergic comorbidities. At present there is a lack of data to support the use of different monitoring strategies directed by asthma phenotypes. The Task Force therefore did not consider the usefulness of particular monitoring tailored to phenotypic presentations.

\section{Risk factors}

Several risk factors have been identified that predict impaired lung function development or accelerated lung function decline, exacerbations, hospital admissions or fatal or near-fatal asthma, and might warrant a more frequent or more extensive monitoring scheme (table 3) [10, 34-40]. 
TABLE 2 Monitoring tools for asthma in children

\begin{tabular}{|c|c|c|c|c|}
\hline & \multicolumn{4}{|c|}{ Age years } \\
\hline & $0-2$ & $2-4$ & $4-6$ & $>6$ \\
\hline \multicolumn{5}{|l|}{ Clinical tools } \\
\hline Symptoms & $x$ & $x$ & $x$ & $x$ \\
\hline С-АСТ/АСТ & - & - & $x$ & $x$ \\
\hline$A C Q$ & - & - & - & $x$ \\
\hline Exacerbations & $x$ & $x$ & $x$ & $x$ \\
\hline QoLQ & - & - & - & $x$ \\
\hline \multicolumn{5}{|l|}{ Lung function } \\
\hline Flow-volume curves/BDR & (Tidal) & (Tidal) & $(x)$ & $x$ \\
\hline PEF & - & - & $(x)$ & $x$ \\
\hline Rint-IOS-FOT & - & $x$ & $x$ & $x$ \\
\hline $\mathrm{LCl}$ & $x$ & $x$ & $x$ & $x$ \\
\hline ILF & $x$ & - & - & - \\
\hline \multicolumn{5}{|l|}{ BHR } \\
\hline Direct (methacholine/histamine) & - & - & $(x)$ & $x$ \\
\hline Indirect (exercise, mannitol) & & & $x^{\#}$ & $x$ \\
\hline \multicolumn{5}{|l|}{ Inflammatory markers } \\
\hline FeNO & $x$ & $x$ & $x$ & $x$ \\
\hline Induced sputum (eosinophils, LTE & - & - & - & $x$ \\
\hline Exhaled breath condensate & - & - & $(x)$ & $x$ \\
\hline
\end{tabular}

C-ACT: Childhood Asthma Control Test; ACT: Asthma Control Test; ACQ: Asthma Control Questionnaire; QoLQ: quality of life questionnaire; BDR: bronchodilator response; PEF: peak expiratory flow; Rint; interrupter resistance; IOS: impulse oscillometry; FOT: forced oscillation technique; LCI: lung clearance index; ILF: infant lung function; BHR: bronchial hyperresponsiveness; $F_{\mathrm{eNO}}$ : fraction of exhaled nitric oxide; $\mathrm{LTE}_{4}$ : leukotriene $\mathrm{E}_{4 ;}$ EPX: eosinophil peroxidase. $\mathrm{x}$ : can be used in this age category; $(\mathrm{x})$ : might be possible to use in this age group in specialised centres. ${ }^{\#}$ : modified exercise challenge possible at preschool age.

Allergy is associated with worsening asthma, and allergen exposure is associated with a higher risk of exacerbation. It is therefore important to establish whether the patient is exposed to relevant allergens, whether new allergic sensitisations are developing, or whether any relevant changes in clinical allergic diseases occur [41, 42]. Questions on aeroallergens or food allergies deserve attention, especially where control is suboptimal, and before any changes in treatment are considered.

Most Task Force members assess risk factors during the first visit; during follow-up visits, Task Force members will usually ask for exacerbations and asthma control in the period between two visits, and will assess other risk factors only in uncontrolled patients.

In children with uncontrolled, PSA who are exposed to relevant allergens, home visits by specialised asthma nurses may provide useful information [24, 43].

Exposure to outdoor and indoor air pollution, tobacco smoke (including maternal smoking during pregnancy) and viral infections also increase the risk of exacerbations and impairment of lung function,

\section{TABLE 3 Risk factors for exacerbations/poor control}

Emergency visit, admission, oral steroid course during previous year

Low FEV1

ACT score $<19$

Low socioeconomic status, low income

Comorbidities (rhinitis, sinusitis, food allergy, reflux)

Severe asthma, high-dose medications

Smoking or exhaled smoke exposure

Reduced symptom perception

Reduced adherence

Persistent eosinophilic airways inflammation

Data from [10, 34-40]. FEV1: forced expiratory volume in $1 \mathrm{~s}$; ACT: Asthma Control Test. 
which might suggest that a more intense monitoring programme is justified [44-56]. Although unfavourable socioeconomic conditions and psychosocial factors may increase the risk of uncontrolled disease, there is a current lack of literature that supports the possible ways of monitoring these factors during childhood. However, such factors are likely to become apparent during follow-up visits.

\section{Levels of care and implementing monitoring schemes}

Monitoring schemes and available tools will differ between levels of care (primary, secondary and tertiary), and optimal monitoring schemes for individual patients through the various healthcare levels are largely unavailable. Therefore, it appears to be impossible to define the minimum, ideal and optimum monitoring schemes for the various healthcare sectors.

In Finland and some other countries, a strategic approach to asthma management as well as education of healthcare professionals at all levels appears to have been effective in reducing the burden of asthma in children [57-59].

In many countries, children who are not controlled on step 2 treatment are referred to specialist care and children with unstable disease on step 4 treatment or higher are treated in specialised tertiary care centres, with or without shared care facilities. Admission to hospital for acute asthma represents a failure of control and should trigger a review of maintenance therapy by an asthma specialist.

Since asthma is difficult to diagnose in preschool children and the response to treatment varies considerably in these children, a low threshold for referring young children for further appraisal and possibly follow-up in specialist care is necessary.

Available monitoring tools in primary and secondary care may differ considerably between countries. For most general practitioners, spirometry and basic allergy diagnostics for inhalant allergies are available, whether in their office or in collaboration with diagnostic centres or hospitals. Allergic sensitisation to food allergens may need further evaluation in specialist care.

In general, secondary care centres at least have spirometry and allergy testing facilities. In most countries, tertiary care centres are fully equipped to conduct complex pulmonary diagnoses and are multidisciplinary in nature, combining the expertise of pulmonologists, allergists and immunologists. Task Force members indicate that access to psychosocial support (for complex behavioural issues) and lung function measurements are generally available for preschool children in tertiary care centres.

\section{Monitoring tools}

Tools for monitoring asthma have to a large extent focused around the measures outlined in table 2 . However, as will be evident from the four papers in the ERR, documentation of the efficacy of these measures in monitoring is generally scarce or lacking.

Traditionally, subjective parameters like daily and nocturnal symptoms and more objective measures such as spirometry, PEF and BHR have been used to assess asthma control. Subsequently, the level of asthma control guides treatment adjustments.

More recently, questionnaires have been developed to assess asthma control in a standardised way, in addition to or including lung function tests (to be reviewed later). In the last 10 years, much attention has been given to markers of inflammation, like FeNO and eosinophils in induced sputum, as objective tests to monitor asthmatic patients.

\section{Clinical tools: symptoms, exacerbations and QoL}

Symptoms and rescue medication use are the easiest clinical tools to apply, are available for all ages and form a distinct domain in the clinical expression of asthma, independent from exacerbations, lung function and inflammation [16]. One should be aware that the use of rescue bronchodilators varies considerably between children and depends highly on the subjective perception of the degree of airway narrowing, or symptoms observed by caregivers in the case of young children. Such symptom-based tools may therefore be an unreliable marker of asthma control in some children [60]. For patients, exacerbations and the limitations that asthma imposes on their daily activities, including sports and play, are the most bothersome and are important aspects to be questioned at every visit [61]. Table 4 summarises the symptoms and consequences of asthma disease activity that most Task Force members discuss at every visit.

There is no evidence supporting the use of diaries to monitor asthma symptoms in clinical practise [62]. However, it cannot be excluded that some individual patients may benefit from daily symptom monitoring in a diary. 
TABLE 4 Symptoms and consequences of asthma disease activity

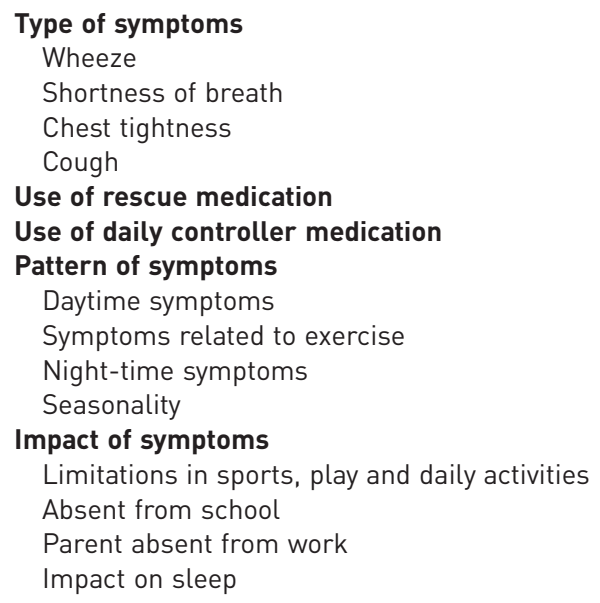

\section{Composite asthma control scores}

Paediatric composite asthma control scores are increasingly being used in asthma management [63]. The Childhood Asthma Control Test (C-ACT), the Asthma Control Test (ACT) and the Asthma Control Questionnaire (ACQ) are instruments that have been studied and validated most extensively [64, 65]. Although a single numerical value to express asthma control is highly attractive, C-ACT, ACT and ACQ do not include exacerbations and future risks, such as lung function decline [66-69]. Therefore, these composite scores appear to underestimate the level of asthma control as defined by GINA [70]. Recently, two composite asthma control scores have been developed that include exacerbations: the Test for Respiratory and Asthma Control in Kids (TRACK) and the Composite Asthma Severity Index (CASI) [71, 72].

Poor asthma control is associated with reduced lung function, increased risk of exacerbations and elevated FeNO [64, 65, 73-77]. Changes in composite measures of asthma control reflect changes in the overall clinical assessment of asthma control by healthcare providers, changes in QoL, and the need to step up or step down therapy, suggesting that these composite measures have criteria validity $[78,79]$.

All Task Force members assess clinical asthma control with an interview, and the use of composite asthma control scores has so far not been shown to improve symptoms or impact on daily life.

\section{E-health and telemonitoring}

Mobile phones and web-based applications offer new possibilities for guided self-management. 21 studies in adults and children were summarised in a Cochrane meta-analysis, which concluded that e-health initiatives did not improve patient QoL or reduce exacerbations and hospital admissions in children [80].

Therefore, to date e-health initiatives have no place in routine clinical care of children with asthma.

\section{Exacerbations}

Asthma exacerbations constitute one of the most troublesome and frightening aspects of asthma to patients and carers [81]. The risk of exacerbations is increased in children with inadequate adherence to controller therapy, poor asthma control, frequent prior exacerbations and elevated FeNO levels, but none of these factors reliably predict exacerbations [82-85]. Obviously, severity, frequency and management of exacerbations outlined in an asthma action plan should be reviewed at each consultation.

All Task Force members ask for exacerbations that have occurred between clinic visits.

QoL

QoL instruments provide independent additional information on asthma status, complementary to symptoms and lung function, and are a potentially useful additional outcome parameter to assess response to longer-term treatment trials $[6,86]$. However, no study has assessed whether asthma management based on usual care plus QoL monitoring is superior to routine asthma management in improving asthma outcomes. 
At present, paediatric asthma QoL questionnaires are too time-consuming and lack documentation of improved clinical outcomes to be part of routine clinical care, and are primarily developed for research purposes [87].

\section{Lung function}

Pulmonary function, and particularly forced expiratory volume in $1 \mathrm{~s}$ (FEV1), is an important component of assessment of asthma control and predictor of future risk to the patient, as reduced lung function is associated with poorer asthma outcomes [88, 89].

Significant bronchial obstruction may be present in asymptomatic asthmatic children. In general, children with chronic airway obstruction are less likely to experience dyspnoea compared with children with acute obstruction $[90,91]$. In contrast, some children may experience dyspnoea without any bronchial obstruction, suggesting that their symptoms are not due to asthma. Therefore, in some but not all guidelines, periodic assessment of maximal flow-volume curves is recommended in asthmatic children aged 5-6 years to optimise asthma management and to ensure therapeutic goals are met $[1,6,7]$. In younger children, lung function may be monitored by other measures, such as impulse oscillometry (IOS) and the forced oscillation technique (FOT), but these are not available outside tertiary care centres in many countries.

\section{Maximal flow-volume curves, peak flow and bronchodilator response}

The measurement of maximal expiratory flow-volume curve parameters is considered the gold standard for the assessment of lung function in children with asthma, and reversibility of airway obstruction is a key feature of asthma. Spirometry every 1-2 years has been recommended by the NAEPP guidelines for children $\geqslant 5$ years of age with asthma, but the BTS and GINA do not provide clear recommendations on monitoring FEV 1 in children $[1,6,7]$. There are several arguments for regular monitoring of FEV1 in asthmatic children. Epidemiological studies have consistently tracked FEV1 and the FEV1/forced vital capacity (FVC) ratio from childhood to adulthood $[88,89]$. FEV1 and persistent bronchodilator response (BDR) might help identify children at risk of developing a progressive decline in lung function [92]. High BDR has been associated with poor asthma control and clinical outcome, increased airway inflammation, BHR and a good response to ICS $[93,94]$. In addition, in the short term, FEV1 measurements may predict exacerbations [36] and FEV1 is considered important in defining asthma severity [36, 95]. While measurement of peripheral airflow obstruction, i.e. forced expiratory flow at 50\% FVC (FEF50\%) and/or FEF from 25 to 75\% FVC (FEF25-75\%), may be more sensitive for the pathophysiological changes in asthma, the value of these measurements in asthma monitoring needs to be established [96].

In children $<5$ years of age, reproducible maximal flow-volume curves are difficult to achieve. In addition, FEV1 may not be sensitive enough and may have a different physiological meaning in comparison to older children [97].

For the reasons mentioned above, office-based spirometry is useful for monitoring asthma in children $\geqslant 5$ years of age when performed at least annually. For children $<5$ years of age, a specialty setting and training may be required.

More frequent spirometry is sometimes indicated depending on the clinical course (e.g. in children with poor perception, recent admission, risk factors of decline, low FEV1). Home spirometry using electronic devices can be performed in selected cases, when symptom-guided treatment is difficult. However, this is not feasible or necessary in most children $[18,98]$.

In asthmatic children with reduced FEV1 and reduced post-BDR FEV1, it is useful to consider further investigations and follow-up in specialist care [99].

All Task Force members assess spirometry to monitor asthma in children $\geqslant 5$ years of age at least annually, and more frequently in patients with reduced lung function or poor asthma control. The evidence indicates that PEF measurements are not useful in monitoring asthma in children. Two randomised controlled trials failed to show a benefit of PEF-guided treatment in comparison to management based on symptoms alone, and the addition of PEF did not enhance self-management even during acute exacerbations $[19,94]$. Peak flow diaries are also unreliable and are poorly accepted by patients $[100,101]$.

\section{Methods used in children $<5$ years of age}

Interrupter resistance (Rint), IOS and FOT measure respiratory resistance as a proxy of airway obstruction and as such, may be used in the diagnosis and in the assessment of treatment response in wheezing children [102-107]. Moreover, tidal flow-volume loops may reflect abnormal breathing patterns and bronchial obstruction. As only limited cooperation is required, these tests are suitable for preschool children [103-105, 108-110]. 
Although Rint, IOS and FOT measurements have some potential as monitoring tools, longitudinal studies confirming their usefulness in the monitoring of wheezing in preschool children are lacking and at present there is insufficient evidence for routine monitoring with Rint, IOS, FOT or tidal flow-volume loops of all (preschool) children with wheezing.

\section{Body plethysmography}

In general, body plethysmographic measurements of lung volumes are restricted to tertiary (or specialised) clinics and have no place in the routine monitoring of asthma in children. In selected cases, body plethysmography may be of help, particularly in the management of difficult and severe asthma [111]. In obese asthmatic children, measurements of specific airway resistance and lung volumes via body plethysmography may differentiate lung function changes due to asthma (elevated specific airway resistance and elevated total lung capacity) from those due to obesity (normal specific airway resistance) [112].

\section{Multiple breath gas washout techniques (lung clearance index)}

The lung clearance index is a measure of ventilation inhomogeneity and is derived from multiple breath washout tests. The lung clearance index is considered to be more sensitive than conventional lung function tests in detecting early airway disease in children with asthma but particularly in children with cystic fibrosis [113]. However, due to the lack of appropriate studies, to date there is no role for multiple breath washout techniques in the routine monitoring of asthma in children.

\section{Infant lung function}

In infants with wheeze, lung function may be assessed with several techniques, such as the analysis of tidal flow-volume breathing loops [114-116], forced expirations (rapid thoracic compression technique or raised volume rapid thoracic compression technique) [115, 117-121] or body plethysmography [122]. Infant lung function testing has been used to define phenotypes in infants with wheeze and to predict treatment effects and prognosis [120, 121, 123-125]; several studies have tracked lung function from infancy to school age $[115-117,119,126-131]$. However, at present there is no data to support the clinical use of infant lung function tests for monitoring wheezing infants.

\section{Bronchial hyperresponsiveness}

One hallmark of asthma is variable airflow obstruction (i.e. the variability in bronchial tone in response to a variety of different stimuli), and BHR can be assessed using bronchial provocation tests. Bronchial provocation tests may be performed with different chemical substances, such as histamine or methacholine which are both considered as nonspecific direct bronchoprovocation tests [132, 133], or by inhaling allergens (specific direct bronchoprovocation tests) [134]. Several other stimuli can also be used, such as physical exercise [135], inhaled cold air [136] and hyperventilation with dry air [137], all of which are indirect bronchial provocation tests. Assessment of BHR using indirect bronchial provocation tests is rapidly influenced by treatment with ICS [138], compared with direct bronchial provocation tests where several months of treatment is required to show an effect [139]. This is of importance when considering bronchial provocation tests as a monitoring tool. One randomised controlled trial in children showed that routine assessment of BHR using methacholine bronchoprovocation is not useful in monitoring asthma in children [140].

Although routine monitoring of BHR is not useful, BHR assessment via methacholine or exercise tests may be of use in children with exercise limitation, poor symptom perception, or those who do not respond to their current treatment or with atypical asthma symptoms. It may also play a moderate role in predicting future asthma [141].

\section{Markers of inflammation}

Chronic airways inflammation is one of the hallmarks of asthma. The following sections focus on the role of noninvasive biomarkers in monitoring asthma and guiding therapy in routine clinical practise.

\section{FeNO}

The most extensively studied biomarker is $\mathrm{FeNO}$, which has been reported to reflect both airway and tissue eosinophilia [142-144]. FeNO can be measured in a noninvasive standardised way and is an attractive technique for use in children, usually from school age onwards [144-146].

Studies incorporating FeNO into management algorithms have used many different protocols, not only in terms of the frequency of measurements but also in the inclusion of other indices of asthma control. The results are variable, with only some showing significant effects such as reduced BHR and higher maximal expiratory flow at 25\% of FVC, and the outcome measures are not consistent across studies [17, 147-150]. There is a view that the potential of this technique has not been fully evaluated and more work is required that evaluates FeNO-based management in appropriate patients and clinical settings. 
In preschool children, there is no published data that considers the utility of FeNO in monitoring asthma control, adjusting therapy or predicting exacerbations. However, some studies imply that elevated FeNO in preschool children is associated with a risk of future wheezing or later asthma, and predicts a decline in lung function in infants with recurrent wheeze [151-154]. FeNO measurements in preschool children have not been standardised and there is insufficient evidence to support the use of such measurements when monitoring preschool children.

A Cochrane review concluded that based on current evidence, FeNO cannot be recommended for routine monitoring of asthma in children [155]. Most Task Force members support this recommendation; however, in children with difficult or uncontrolled asthma, FeNO is sometimes used for monitoring disease in specialist centres. Persistently high FeNO should alert the physician of reduced adherence to treatment, a faulty inhalation technique, ongoing allergen exposure or severe airways inflammation [146].

\section{Sputum analysis}

Induced sputum cytology analysis is recognised as a noninvasive tool that allows the assessment of inflammatory cells, such as eosinophils and neutrophils, as well as the investigation of a variety of fluid phase mediators in supernatants.

Sputum induction is feasible and safe in asthmatic children, and the technique of sputum induction and processing has been standardised for schoolchildren [25, 156-158]. Percentage of eosinophils is the marker used most frequently in clinical studies. Elevated sputum eosinophils were reported to be predictive of failed ICS reduction and asthma exacerbations in mild-to-moderate asthma, but incorporating the control of sputum eosinophils into the management algorithm did not significantly reduce overall exacerbations or improve asthma control in severe asthma $[25,159,160]$. This may be due to the observation that sputum inflammatory phenotypes are not stable over time [161].

Therefore, there is no evidence that induced sputum cytology is useful for monitoring asthma. None of the Task Force members uses this technique in routine clinical practise. However, for specific patients in specialised tertiary centres, this method may be justified when treatment decisions are difficult to make.

\section{Exhaled breath condensate}

The analysis of exhaled breath condensate (EBC) has been increasingly used as a research tool and many different components of EBC have been assessed. This is a simple, well-tolerated and safe method, even in children with severe asthma [162]. However, even though a joint American Thoracic Society (ATS)/ERS Task Force document was published on the methodology of EBC, technical issues and a lack of standardisation remain major issues that prevent the use of EBC in clinical practise [163]. To date, EBC does not play a role in monitoring asthma in children.

\section{Management-related issues, comorbidities and the environment}

In this section, we discuss aspects of treatment that may be checked to monitor asthma routinely (adherence to treatment, inhalation technique, side-effects of treatment) or as clinically indicated, particularly in the case of poorly controlled asthma (e.g. persisting exposures to tobacco smoke or allergens). Conditions that may aggravate asthma (e.g. allergic rhinitis, environmental irritant exposure) or may become apparent during follow-up (e.g. allergic rhinitis or obesity) are also discussed here.

\section{Adherence to treatment}

Adherence to treatment is defined as the extent to which the patient continues the agreed-upon treatment under limited supervision. More recently, the term "concordance" has been used to express the collaborative relationship between care-taker and care-provider on the basis of equality. The Task Force members chose to use "adherence" in the present paper as in general this is the more commonly used term.

Adherence to ICS is strongly influenced by the patients' and parents' illness and medication beliefs [145, 164-166]. Repeated tailored education, agreement on treatment goals and how to reach these, and addressing patients' and parents' beliefs and concerns therefore help to improve adherence to treatment and hence asthma control [164, 167-171]. Risk factors for decreased adherence include growing up in a single-parent family or replacement of the caregiver, and being prescribed more than two puffs a day [168, $172,173]$.

There is no gold standard for the measurement of adherence to treatment. Self-reporting by the patient or caregiver, and pharmacy refill rates tend to overestimate adherence [174]. Electronic data recording could be superior; however, this should be balanced against extra costs [175]. Face-to-face interviews are more effective in reporting adherence than computer-assisted or pencil and paper interviews; however, all three 
methods considerably overestimate adherence in comparison with electronic measurement [175]. Motivational interviews are a patient-centred approach used to discuss behavioural changes and a considerable body of evidence suggests that adherence can be improved by applying specific communicative consultation skills [176].

Several members of the Task Force routinely discuss adherence to treatment in a non-confrontational way as part of every asthma review. In children with severe, uncontrolled asthma, there are several ways of assessing adherence: electronic measurement and directly observed therapy are the most reliable, and if these are unavailable prescription records or refill rates could provide useful information. In some cases, home visits may be useful [43].

\section{Inhaler technique}

Correct inhaler technique is one of the prerequisites of successful asthma treatment. In children, this might be challenging as less than one-third of asthmatic children using a dry powder inhaler and two-thirds of children using a pressurised metered-dose inhaler/spacer combination perform all essential steps correctly [177]. The evidence suggests that inhalation technique should be taught, taught back and checked at least twice when new drugs or devices are prescribed, when asthma control deteriorates or at least annually $[178,179]$. In addition, in young children, parents are usually asked to demonstrate inhaler technique at each visit and advice may be given about correct administration. In agreement with the ERS/ International Society of Aerosols in Medicine (ISAM) consensus paper on inhalation, all Task Force members check the technique for each type of inhaler device according to the device-specific recommendations [180].

\section{Side-effects of drug treatment}

The risk of systemic side-effects during long-term use of low-to-moderate doses of ICS (beclometasone $200-400 \mu \mathrm{g} \cdot \mathrm{day}^{-1}$ or equivalent) is considered rare [181, 182]. Height growth may be reduced by $\sim 0.5-$ $2 \mathrm{~cm}$ during the first 1-2 years of treatment; whether or not this persists over time is under debate but cannot be excluded [183-185]. Adrenal suppression is more frequently seen during treatment with high-dose ICS; however, the frequency and severity of hypothalamic-pituitary-adrenal axis suppression is highly dependent on the tests used to assess this axis, and one should be aware that adrenal insufficiency may occur at low-to-moderate doses of ICS $[186,187]$. More research is needed to define which tests for adrenal suppression are useful in which children. Nasal and dermal corticosteroids have to be considered in assessing total corticosteroid dose.

Local side-effects, such as thrush and hoarseness, are rare and are in general easily managed by teeth brushing or mouth rinsing after administration of ICS [188].

Side-effects of other medications given to control asthma, such as $\beta_{2}$-agonists and leukotriene antagonists, are also considered during monitoring by the Task Force members. However, there is limited evidence to support the need for specific investigations that monitor drugs other than corticosteroids.

In children using ICS, all Task Force members measure height and weight at least annually, but preferably at every visit. Children using high doses of ICS deserve special attention and monitoring for possible adrenal suppression.

\section{Monitoring diseases that may aggravate asthma}

Rhinitis, food allergy, gastro-oesophageal reflux (GOR) and obesity are conditions that may aggravate or mimic asthma; however, there is currently no evidence that treatment of these conditions improves asthma control [189]. There is no role for routine monitoring of these diseases in children with asthma; however, appropriate diagnostics might be considered for these diseases in children with uncontrolled asthma.

Asthmatic children with rhinitis, compared to those without, have poorer asthma control, reduced QoL, an increased risk of emergency visits or hospitalisations, and higher healthcare costs [41, 190-192]. Therefore, signs and symptoms suggestive of rhinitis and rhinosinusitis are often discussed and although treatment for rhinitis has not been proven to improve asthma control, it is considered good practise to ensure that rhinitis symptoms are managed appropriately in children with asthma.

Food allergy is commonly considered to be a risk factor for poor asthma control, and it may cause severe and even fatal asthma exacerbations, although food allergy in most studies has not been diagnosed with a double-blind-placebo-controlled food challenge [86, 193]. However, it appears that not the food allergy per se but sensitisation to multiple foods and aeroallergens is a risk factor associated with poor asthma control or severe exacerbations [194-196]. After appropriate counselling, children with comorbid food anaphylaxis might be considered for receiving an adrenaline auto-injector and appropriate training in its use [197]. 
GOR has been suggested as a cause of poor asthma control in children but treatment with lansoprazole in children with poorly controlled asthma, without symptoms of GOR, improves neither symptoms nor lung function [198-201]. There is no role for the routine assessment of GOR or swallowing abnormalities in children with asthma.

The relationship between obesity and asthma is complex and as yet not completely understood [202-206]. All Task Force members measure height and weight during routine clinical monitoring, with calculation of body mass index or percentile estimates of weight and height based on a relevant population.

\section{Environmental factors}

Multiple indoor and outdoor environmental stimuli are known to worsen asthma symptoms. The most common stimuli are discussed here; these include exposure to tobacco smoke, combustion-derived air pollutants, house dust mites, fungal spores, pollens and pet dander.

\section{Tobacco smoke}

There is good evidence that second-hand tobacco smoke exposure causes asthma, more severe asthma symptoms, BHR, airways inflammation and adverse effects on respiratory health in children [207-210]. There can be no doubt that smoking in the parents or caregivers should be strongly discouraged [44, 207209, 211]. Success rates in asthma education, including second-hand smoke harm awareness, are low but in children who live in households where tobacco smoke exposure was successfully reduced, hospital admissions were halved over the following year [212]. A better understanding of how to motivate parents of children with asthma to change their smoking habits is urgently needed [213, 214].

Several methods are used to objectively measure children's second hand smoke exposure (cotinine, hair or nail nicotine, exhaled carbon monoxide, airborne nicotine) but a gold standard is lacking and currently there is no single recommended method for monitoring such exposure in children with asthma or for monitoring maternal smoking during pregnancy.

Air pollution

Children are more vulnerable to the health effects of outdoor and indoor air pollution than adults as their lungs are still developing, they have a higher minute ventilation, and they have higher levels of physical activity outdoors [215-218]. There is a positive association between exposure to traffic-related air pollution and exacerbation of asthma symptoms in children and reduced growth in lung function [47, 52, 54, 219 , 220]. However, the measurement of outdoor pollutants is mainly performed for regulatory purposes and is not currently used to monitor asthma in children.

Indoor pollutants are mainly derived from incomplete combustion of biomass and solid fuels (e.g. dung, wood, agricultural residues, charcoal, coal, kerosene, candles, incense and mosquito coils) $[50,51,55,56]$. Children seem to be more vulnerable to the effects of indoor pollution, and chronic exposure to indoor pollutants is associated with persistent wheeze, current asthma and use of asthma medication in children $[45,46,49,51]$. Indoor dampness is another important factor that imposes a higher risk of asthma $[48,53]$.

Home visits by an asthma nurse are often conducted in patients with severe uncontrolled asthma to check for aggravating factors in the home.

\section{Environmental allergen load}

House dust mites, pollens, pet allergens and fungal spores are amongst the most common allergens in the indoor and outdoor environment. Single measures to reduce indoor allergen loads are likely to be of little benefit; individualised intervention programmes may reduce exposure to indoor allergens and result in decreased asthma morbidity, but a recent meta-analysis showed that measures to reduce house dust mite exposure were not helpful [221-223]. Specific questions about environmental exposures that are likely to increase the risk of asthma or to trigger asthma exacerbations are generally included in the assessment of all asthmatic children (table 5). Local air quality websites may be checked for warnings of high levels of air pollution and pollen loads, and precautions may be taken accordingly.

Monitoring through home visits to specifically assess the environmental allergen load could assist in the management of children with difficult-to-treat asthma before any changes to treatment regimens are considered [43].

\section{Knowledge gaps and research needs in monitoring childhood asthma} Several research gaps were identified by this Task Force.

It is obvious that symptom control, prevention of exacerbations or lung function decline, and lack of lung growth represent three different clinical outcomes that may require different monitoring strategies. In 
TABLE 5 List of possible pollutants/sources to be discussed with parents and children in the clinic or during a home visit

Exhaled tobacco smoke exposure

Traffic density near home/school

Industries near home/school

Cooking: use of wood/gas

Type of heating: any use of biomass

Pets: dogs/cats

House dust mite

Mould

Chemicals used at home for cleaning

Use of incense sticks/candles

addition, several studies demonstrate a number of parameters that can be used to assess asthma control in children through a single examination, but follow-up studies assessing the usefulness of these parameters in monitoring asthma are lacking. The variability of the pathophysiology in asthma is not in parallel, e.g. inflammation and bronchial obstruction may independently vary in time, underpinning the need for the availability of several tools for longitudinal monitoring. There is therefore an urgent need for studies that consider more targeted monitoring strategies in specific populations. Personalised medicine asks for personalised monitoring, which is not possible yet.

To date, phenotypic description of asthma has not been helpful in choosing monitoring schemes, and studies are needed not only to assess the effectiveness of asthma phenotypes per se but also take complex allergic diseases into consideration, regardless of whether they constitute certain phenotypes.

Studies that assess the usefulness of composite asthma control scores and longitudinal QoL measures in improving asthma control in primary and secondary care are needed.

Clinical trials that assess the utility of FeNO in adjusting treatment or in predicting exacerbations in specific phenotypes, such as obese children, children with severe persistent asthma or preschool children, have not been performed. In addition, the meaning of significant changes in FeNO in a longitudinal setting is still unclear and needs further attention. The use of "personal best" cut-off points in FeNO algorithms requires further investigation.

In the same way, the feasibility and utility of induced sputum cytology to guide treatment in schoolchildren with mild-to-moderate asthma and preschool children with wheezing has yet to be investigated.

The use of lung function testing and noninvasive markers in preschool children is of particular interest and although their role in monitoring may be limited, their role in predicting the development of asthma and showing those who might benefit from ICS is a real challenge.

There is a general lack of monitoring schemes that are optimal for different healthcare settings, disease severities and ages. Data on optimal frequency of follow-up, tools to be used at each level and health costbenefit are lacking. All these issues warrant further study.

\section{Conclusion}

Monitoring asthma in children requires careful review of the impact of asthma on the child's daily life, including sports and play. Adherence to maintenance therapy, inhaler technique and the patients' (and parents') views and beliefs on the goals of treatment are essential in monitoring children with asthma. The use of composite asthma control scores has not been shown to improve asthma outcome and QoL measures, and though potentially useful in research, they have limited value in clinical practise. Spirometry with BDR is of value and should be performed at least annually and more frequently in risk groups. There is no evidence that measurements of bronchial responsiveness and markers of inflammation are useful in the routine monitoring of children with asthma.

In children with poor asthma control, it is necessary to screen for allergic or non-allergic rhinitis/ rhino-sinusitis and other comorbidities, and for exposure to indoor pollutants like tobacco smoke and allergens.

\section{Acknowledgements}

The Task Force members are grateful to Irma Stok-Beckers (Sophia Children's Hospital, Erasmus MC, Rotterdam, the Netherlands) who was a great help with editing the references. 


\section{References}

1 National Asthma Education and Prevention Program. Expert panel report 3 (EPR-3): guidelines for the diagnosis and management of asthma - summary report 2007. J Allergy Clin Immunol 2007; 120: Suppl. 5, S94-S138.

2 Saglani S, Payne DN, Zhu J, et al. Early detection of airway wall remodeling and eosinophilic inflammation in preschool wheezers. Am J Respir Crit Care Med 2007; 176: 858-864.

3 Saglani S, Malmstrom K, Pelkonen AS, et al. Airway remodeling and inflammation in symptomatic infants with reversible airflow obstruction. Am J Respir Crit Care Med 2005; 171: 722-727.

4 Reddel HK, Taylor DR, Bateman ED, et al. An official American Thoracic Society/European Respiratory Society statement: asthma control and exacerbations: standardizing endpoints for clinical asthma trials and clinical practice. Am J Respir Crit Care Med 2009; 180: 59-99.

5 Bacharier LB, Boner A, Carlsen KH, et al. Diagnosis and treatment of asthma in childhood: a PRACTALL consensus report. Allergy 2008; 63: 5-34.

6 British Thoracic Society Scottish Intercollegiate Guidelines. British guideline on the management of asthma. Thorax 2008; 63: Suppl. 4, iv1-iv121.

7 Global Initiative for Asthma. Global Strategy for Asthma Management and Prevention, revised 2014. Available from www.ginasthma.org

8 Fuhlbrigge AL, Guilbert T, Spahn J, et al. The influence of variation in type and pattern of symptoms on assessment in pediatric asthma. Pediatrics 2006; 118: 619-625.

9 Gustafsson PM, Watson L, Davis KJ, et al. Poor asthma control in children: evidence from epidemiological surveys and implications for clinical practice. Int J Clin Pract 2006; 60: 321-334.

10 Chipps BE, Zeiger RS, Borish L, et al. Key findings and clinical implications from the epidemiology and natural history of asthma: outcomes and treatment tegimens (TENOR) study. J Allergy Clin Immunol 2012; 130: $332-342$.

11 Moeller A, Carlsen K-H, Sly PD, et al. Monitoring of asthma in children: lung function, bronchial responsiveness and inflammation. Eur Respir Rev 2015; [In press DOI: 10.1183/16000617.00003914].

12 Brand PLP, Mäkelä M, Szefler SJ, et al. Monitoring of asthma in children: symptoms, exacerbations and quality of life. Eur Respir Rev 2015; [In press DOI: 10.1183/16000617.00003614].

13 Lødrup Carlsen KC, Pijnenburg MW. Monitoring of asthma in children. Eur Respir Rev 2015; [In press DOI: 10.1183/ 16000617.00003714].

14 Rottier BL, Eber E, Hedlin G, et al. Monitoring of asthma in children: management-related issues. Eur Respir Rev 2015; [In press DOI: 10.1183/16000617.00003814].

15 Koh MS, Irving LB. The natural history of asthma from childhood to adulthood. Int J Clin Pract 2007; 61: 1371-1374.

16 Holt EW, Cook EF, Covar RA, et al. Identifying the components of asthma health status in children with mild to moderate asthma. J Allergy Clin Immunol 2008; 121: 1175-1180.

17 de Jongste JC, Carraro S, Hop WC, et al. Daily telemonitoring of exhaled nitric oxide and symptoms in the treatment of childhood asthma. Am J Respir Crit Care Med 2009; 179: 93-97.

18 Deschildre A, Beghin L, Salleron J, et al. Home telemonitoring (forced expiratory volume in $1 \mathrm{~s}$ ) in children with severe asthma does not reduce exacerbations. Eur Respir J 2012; 39: 290-296.

19 Wensley D, Silverman M. Peak flow monitoring for guided self-management in childhood asthma - a randomized controlled trial. Am J Respir Crit Care Med 2004; 170: 606-612.

20 Klok T, de Groot EP, Brouwer AFJ, et al. Follow-up of children with asthma. In: Carlsen K-H, Gerritsen J, eds. Paediatric Asthma. ERS Monogr 2012; 56: 210-223.

21 Rikkers-Mutsaerts ERVM, Winters AE, Bakker MJ, et al. Internet-based self-management compared with usual care in adolescents with asthma: a randomized controlled trial. Pediatr Pulm 2012; 47: 1170-1179.

22 Hedlin G, Bush A, Carlsen KL, et al. Problematic severe asthma in children, not one problem but many: a GA(2) LEN initiative. Eur Respir J 2010; 36: 196-201.

23 Lang A, Carlsen $\mathrm{KH}$, Haaland G, et al. Severe asthma in childhood: assessed in 10 year olds in a birth cohort study. Allergy 2008; 63: 1054-1060.

24 Lodrup Carlsen KC, Hedlin G, Bush A, et al. Assessment of problematic severe asthma in children. Eur Respir J 2011; 37: 432-440.

25 Fleming L, Wilson N, Regamey N, et al. Use of sputum eosinophil counts to guide management in children with severe asthma. Thorax 2012; 67: 193-198.

26 Spycher BD, Silverman M, Kuehni CE. Phenotypes of childhood asthma: are they real? Clin Exp Allergy 2010; 40: $1130-1141$.

27 Bousquet J, Anto J, Auffray C, et al. MeDALL (Mechanisms of the Development of ALLergy): an integrated approach from phenotypes to systems medicine. Allergy 2011; 66: 596-604.

28 Lotvall J, Akdis CA, Bacharier LB, et al. Asthma endotypes: a new approach to classification of disease entities within the asthma syndrome. J Allergy Clin Immunol 2011; 127: 355-360.

29 Saglani S, Bush A. Asthma, atopy, and airway inflammation: what does it mean in practice? Am J Respir Crit Care Med 2008; 178: 437-438.

30 Saglani S, Bush A. The early-life origins of asthma. Curr Opin Allergy Clin Immunol 2007; 7: 83-90.

31 Szefler SJ, Martin RJ, King TS, et al. Significant variability in response to inhaled corticosteroids for persistent asthma. J Allergy Clin Immunol 2002; 109: 410-418.

32 Szefler SJ, Phillips BR, Martinez FD, et al. Characterization of within-subject responses to fluticasone and montelukast in childhood asthma. J Allergy Clin Immunol 2005; 115: 233-242.

33 Brasier AR, Victor S, Ju $\mathrm{H}$, et al. Predicting intermediate phenotypes in asthma using bronchoalveolar lavage-derived cytokines. Clin Transl Sci 2010; 3: 147-157.

34 Etzel RA. How environmental exposures influence the development and exacerbation of asthma. Pediatrics 2003; 112: 233-239.

35 Forno E, Fuhlbrigge A, Soto-Quiros ME, et al. Risk factors and predictive clinical scores for asthma exacerbations in childhood. Chest 2010; 138: 1156-1165.

36 Fuhlbrigge AL, Kitch BT, Paltiel AD, et al. $\mathrm{FEV}(1)$ is associated with risk of asthma attacks in a pediatric population. J Allergy Clin Immunol 2001; 107: 61-67. 
Lee YJ, Kim KW, Choi BS, et al. Clinical characteristics of eosinophilic and noneosinophilic asthma in children. Acta Paediatrica 2013; 102: 53-57.

McCarville M, Sohn MW, Oh E, et al. Environmental tobacco smoke and asthma exacerbations and severity: the difference between measured and reported exposure. Arch Dis in Child 2013; 98: 510-514.

McConnochie KM, Russo MJ, McBride JT, et al. Socioeconomic variation in asthma hospitalization: excess utilization or greater need? Pediatrics 1999; 103: e75.

Schatz M, Zeiger RS, Yang SJ, et al. The relationship of asthma impairment determined by psychometric tools to future asthma exacerbations. Chest 2012; 141: 66-72.

de Groot EP, Nijkamp A, Duiverman EJ, et al. Allergic rhinitis is associated with poor asthma control in children with asthma. Thorax 2012; 67: 582-587.

Thomas M, Kocevar VS, Zhang QY, et al. Asthma-related health care resource use among asthmatic children with and without concomitant allergic rhinitis. Pediatrics 2005; 115: 129-134.

Bracken M, Fleming L, Hall P, et al. The importance of nurse-led home visits in the assessment of children with problematic asthma. Arch Dis Child 2009; 94: 780-784.

Kalliola S, Pelkonen AS, Malmberg LP, et al. Maternal smoking affects lung function and airway inflammation in young children with multiple-trigger wheeze. J Allergy Clin Immun 2013; 131: 730-735.

Azizi BH, Henry RL. The effects of indoor environmental factors on respiratory illness in primary school children in Kuala Lumpur. Int J Epidemiol 1991; 20: 144-150.

Fagbule D, Ekanem EE. Some environmental risk factors for childhood asthma: a case-control study. Ann Trop Paediatr 1994; 14: 15-19.

Health Effects Institute. Traffic-Related Air Pollution: a Critical Review of the Literature on Emissions, Exposure, and Health Effects. Boston, Health Effects Institute, 2010.

Kilpelainen M, Terho EO, Helenius H, et al. Home dampness, current allergic diseases, and respiratory infections among young adults. Thorax 2001; 56: 462-467.

Koo LC, Ho JH-C. Mosquito coil smoke and respiratory health among Hong Kong Chinese: results of three epidemiological studies. Indoor and Built Environment 1994; 3: 304-310.

Lin TC, Krishnaswamy G, Chi DS. Incense smoke: clinical, structural and molecular effects on airway disease. Clin Mol Allergy 2008; 6: 3.

Liu W, Zhang J, Hashim JH, et al. Mosquito coil emissions and health implications. Environ Health Perspect 2003; 111: 1454-1460.

Nastos PT, Paliatsos AG, Anthracopoulos MB, et al. Outdoor particulate matter and childhood asthma admissions in Athens, Greece: a time-series study. Environ Health 2010; 9: 45.

Quansah R, Jaakkola MS, Hugg TT, et al. Residential dampness and molds and the risk of developing asthma: a systematic review and meta-analysis. PLoS One 2012; 7: e47526.

Spira-Cohen A, Chen LC, Kendall M, et al. Personal exposures to traffic-related air pollution and acute respiratory health among Bronx schoolchildren with asthma. Environ Health Perspect 2011; 119: 559-565.

Torres-Duque C, Maldonado D, Perez-Padilla R, et al. Biomass fuels and respiratory diseases: a review of the evidence. Proc Am Thorac Soc 2008; 5: 577-590.

Wang IJ, Tsai $\mathrm{CH}$, Chen $\mathrm{CH}$, et al. Glutathione S-transferase, incense burning and asthma in children. Eur Respir J 2011; 37: 1371-1377.

Haahtela T, Tuomisto LE, Pietinalho A, et al. A 10 year asthma programme in Finland: major change for the better. Thorax 2006; 61: 663-670.

Kupczyk M, Haahtela T, Cruz AA, et al. Reduction of asthma burden is possible through National Asthma Plans. Allergy 2010; 65: 415-419.

Kauppi P, Linna M, Martikainen J, et al. Follow-up of the Finnish Asthma Programme 2000-2010: reduction of hospital burden needs risk group rethinking. Thorax 2013; 68: 292-293.

Brouwer AF, Brand PL, Roorda RJ, et al. Airway obstruction at time of symptoms prompting use of reliever therapy in children with asthma. Acta Paediatrica 2010; 99: 871-876.

Wildhaber J, Carroll WD, Brand PL. Global impact of asthma on children and adolescents' daily lives: the room to breathe survey. Pediatr Pulmonol 2012; 47: 346-357.

Arga M, Sahbaz H, Bakirtas A, et al. Does self-monitoring by means of symptom diaries improve asthma control in children? J Asthma 2014; 51: 299-305.

Cloutier MM, Schatz M, Castro M, et al. Asthma outcomes: composite scores of asthma control. J Allergy Clin Immunol 2012; 129: Suppl. 3, S24-S33.

Liu AH, Zeiger R, Sorkness C, et al. Development and cross-sectional validation of the Childhood Asthma Control Test. J Allergy Clin Immunol 2007; 119: 817-825.

Juniper EF, Gruffydd-Jones K, Ward S, et al. Asthma control questionnaire in children: validation, measurement properties, interpretation. Eur Respir J 2010; 36: 1410-1416.

6 Bousquet J, Mantzouranis E, Cruz AA, et al. Uniform definition of asthma severity, control, and exacerbations: Document presented for the World Health Organization Consultation on Severe Asthma. J Allergy Clin Immunol 2010; 126: 926-938.

Bateman ED, Reddel HK, Eriksson G, et al. Overall asthma control: the relationship between current control and future risk. J Allergy Clin Immunol 2010; 125: 600-608.

Wu AC, Tantisira K, Li LL, et al. Predictors of symptoms are different from predictors of severe exacerbations from asthma in children. Chest 2011; 140: 100-107.

Koster ES, Raaijmakers JAM, Vijverberg SJH, et al. Limited agreement between current and long-term asthma control in children: the PACMAN cohort study. Pediat Allerg Imm-Uk 2011; 22: 776-783.

Koolen BB, Pijnenburg MW, Brackel HJ, et al. Comparing global initiative for asthma (GINA) criteria with the childhood asthma control test (C-ACT) and asthma control test (ACT). Eur Respir J 2011; 38: 561-566.

Murphy KR, Zeiger RS, Kosinski M, et al. Test for Respiratory and Asthma Control in Kids (TRACK): a caregiver-completed questionnaire for preschool-aged children. J Allergy Clin Immunol 2009; 123: 833-839.

2 Wildfire JJ, Gergen PJ, Sorkness CA, et al. Development and validation of the Composite Asthma Severity Index - an outcome measure for use in children and adolescents. J Allergy Clin Immunol 2012; 129: 694-701. 
de Blic J, Boucot I, Pribil C, et al. Control of asthma in children: still unacceptable? A French cross-sectional study. Respir Med 2009; 103: 1383-1391.

Piacentini GL, Peroni DG, Bodini A, et al. Childhood asthma control test and airway inflammation evaluation in asthmatic children. Allergy 2009; 64: 1753-1757.

Stanford RH, Gilsenan AW, Ziemiecki R, et al. Predictors of uncontrolled asthma in adult and pediatric patients analysis of the asthma control characteristics and prevalence survey studies (ACCESS). J Asthma 2010; 47: $257-262$.

Ito Y, Adachi Y, Itazawa $\mathrm{T}$, et al. Association between the results of the childhood asthma control test and objective parameters in asthmatic children. J Asthma 2011; 48: 1076-1080.

van Dalen C, Harding E, Parkin J, et al. Suitability of forced expiratory volume in 1 second/forced vital capacity $v s$ percentage of predicted forced expiratory volume in 1 second for the classification of asthma severity in adolescents. Arch Pediat Adol Med 2008; 162: 1169-1174.

Chipps B, Zeiger RS, Murphy K, et al. Longitudinal validation of the test for respiratory and asthma control in kids in pediatric practices. Pediatrics 2011; 127: E737-E747.

Voorend-van Bergen S, Brackel H, Caudri D, et al. Assessment of asthma control by children and parents. Eur Respir J 2013; 41: 233-234.

McLean S, Chandler D, Nurmatov U, et al. Telehealthcare for asthma: a Cochrane review. Can Med Assoc J 2011; 183: E733-E742.

Carroll WD, Wildhaber J, Brand PLP. Parent misperception of control in childhood/adolescent asthma: the Room to Breathe survey. Eur Respir J 2012; 39: 90-96.

Fuhrman C, Dubus JC, Marguet C, et al. Hospitalizations for asthma in children are linked to undertreatment and insufficient asthma education. J Asthma 2011; 48: 565-571.

Ungar WJ, Paterson JM, Gomes T, et al. Relationship of asthma management, socioeconomic status, and medication insurance characteristics to exacerbation frequency in children with asthma. Ann Allergy Asthma Immunol 2011; 106: 17-23.

Visser CA, Brand PL. Does a single measurement of exhaled nitric oxide predict asthma exacerbations? Arch Dis Child 2011; 96: 781-782.

Williams LK, Peterson EL, Wells K, et al. Quantifying the proportion of severe asthma exacerbations attributable to inhaled corticosteroid nonadherence. J Allergy Clin Immunol 2011; 128: 1185-1191.

Gillman A, Douglass JA. What do asthmatics have to fear from food and additive allergy? Clin Exp Allergy 2010; 40: $1295-1302$.

Wilson SR, Rand CS, Cabana MD, et al. Asthma outcomes: quality of life. J Allergy Clin Immunol 2012; 129: Suppl. 3, S88-S123.

Oswald H, Phelan PD, Lanigan A, et al. Childhood asthma and lung function in mid-adult life. Pediatr Pulmonol 1997; 23: 14-20.

Sears MR, Greene JM, Willan AR, et al. A longitudinal, population-based, cohort study of childhood asthma followed to adulthood. N Engl J Med 2003; 349: 1414-1422.

Tosca MA, Silvestri M, Olcese R, et al. Breathlessness perception assessed by visual analogue scale and lung function in children with asthma: a real-life study. Pediatr Allergy Immunol 2012; 23: 537-542.

Baker RR, Mishoe SC, Zaitoun FH, et al. Poor perception of airway obstruction in children with asthma. J Asthma 2000; 37: 613-624.

Liu AH. Biomarkers and childhood asthma: improving control today and tomorrow. Allergy Asthma Proc 2005; 26: 249-254.

Galant SP, Morphew T, Newcomb RL, et al. The relationship of the bronchodilator response phenotype to poor asthma control in children with normal spirometry. J Pediatr 2011; 158: 953-959.

Tantisira KG, Fuhlbrigge AL, Tonascia J, et al. Bronchodilation and bronchoconstriction: predictors of future lung function in childhood asthma. J Allergy Clin Immunol 2006; 117: 1264-1271.

National Asthma Education and Prevention Program. National asthma education and prevention program. Expert panel report: guidelines for the diagnosis and management of asthma update on selected topics - 2002. J Allergy Clin Immunol 2002; 110: Suppl. 5, S141-S219.

Jones MH, Howard J, Davis S, et al. Sensitivity of spirometric measurements to detect airway obstruction in infants. Am J Respir Crit Care Med 2003; 167: 1283-1286.

Vonk JM, Postma DS, Boezen HM, et al. Childhood factors associated with asthma remission after 30 year follow up. Thorax 2004; 59: 925-929.

Brouwer AF, Roorda RJ, Brand PL. Home spirometry and asthma severity in children. Eur Respir J 2006; 28: 1131-1137.

Miller MR, Hankinson J, Brusasco V, et al. Standardisation of spirometry. Eur Respir J 2005; 26: 319-338.

Kamps AW, Roorda RJ, Brand PL. Peak flow diaries in childhood asthma are unreliable. Thorax 2001; 56 $180-182$.

Harver A, Humphries CT, Kotses H. Do asthma patients prefer to monitor symptoms or peak flow? J Asthma 2009; 46: 940-943.

373-383.

Goldman MD. Clinical application of forced oscillation. Pulm Pharmacol Ther 2001; 14: 341-350.

4 Klug B, Bisgaard H. Measurement of lung function in awake 2-4-year-old asthmatic children during methacholine challenge and acute asthma: a comparison of the impulse oscillation technique, the interrupter technique, and transcutaneous measurement of oxygen versus whole-body plethysmography. Pediatr Pulmonol 1996; 21: 290-300.

105 McKenzie SA, Bridge PD, Pao CS. Lung function tests for pre-school children. Paediatr Respir Rev 2001; 2: $37-45$.

Hellinckx J, De Boeck K, Bande-Knops J, et al. Bronchodilator response in 3-6.5 years old healthy and stable asthmatic children. Eur Respir J 1998; 12: 438-443.

Malmberg LP, Makela MJ, Mattila PS, et al. Exercise-induced changes in respiratory impedance in young wheezy children and nonatopic controls. Pediatr Pulm 2008; 43: 538-544. 

function techniques in asthmatic and healthy children aged 2 to 5 years. Am J Respir Crit Care Med 2001; 164: 554-559.

109 Oostveen E, Dom S, Desager K, et al. Lung function and bronchodilator response in 4-year-old children with different wheezing phenotypes. Eur Respir J 2010; 35: 865-872.

110 Thamrin C, Gangell CL, Udomittipong K, et al. Assessment of bronchodilator responsiveness in preschool children using forced oscillations. Thorax 2007; 62: 814-819.

111 Jenkins HA, Cherniack R, Szefler SJ, et al. A comparison of the clinical characteristics of children and adults with severe asthma. Chest 2003; 124: 1318-1324.

112 Mahut B, Beydon N, Delclaux C. Overweight is not a comorbidity factor during childhood asthma: the GrowthOb study. Eur Respir J 2012; 39: 1120-1126.

113 Macleod KA, Horsley AR, Bell NJ, et al. Ventilation heterogeneity in children with well controlled asthma with normal spirometry indicates residual airways disease. Thorax 2009; 64: 33-37.

114 Stocks J, Godfrey S, Beardsmore C, et al. Plethysmographic measurements of lung volume and airway resistance. ERS/ATS task force on standards for infant respiratory function testing. European Respiratory Society/American Thoracic Society. Eur Respir J 2001; 17: 302-312.

115 Young S, Arnott J, O'Keeffe PT, et al. The association between early life lung function and wheezing during the first 2 yrs of life. Eur Respir J 2000; 15: 151-157.

116 Haland G, Carlsen KC, Sandvik L, et al. Reduced lung function at birth and the risk of asthma at 10 years of age. N Engl J Med 2006; 355: 1682-1689.

117 Martinez FD, Wright AL, Taussig LM, et al. Asthma and wheezing in the first six years of life. The Group Health Medical Associates. N Engl J Med 1995; 332: 133-138.

118 Turner SW, Palmer LJ, Rye PJ, et al. Infants with flow limitation at 4 weeks: outcome at 6 and 11 years. Am J Respir Crit Care Med 2002; 165: 1294-1298.

119 Turner SW, Young S, Goldblatt J, et al. Childhood asthma and increased airway responsiveness: a relationship that begins in infancy. Am J Respir Crit Care Med 2009; 179: 98-104.

120 Moeller A, Franklin P, Hall GL, et al. Inhaled fluticasone dipropionate decreases levels of nitric oxide in recurrenty wheezy infants. Pediatr Pulmonol 2004; 38: 250-255.

121 Straub DA, Moeller A, Minocchieri S, et al. The effect of montelukast on lung function and exhaled nitric oxide in infants with early childhood asthma. Eur Respir J 2005; 25: 289-294.

122 Pelkonen AS, Kotaniemi-Syrjanen A, Malmstrom K, et al. Clinical findings associated with abnormal lung function in children aged 3-26 months with recurrent respiratory symptoms. Acta Paediatr 2010; 99: 1175-1179.

123 Mallol J, Aguirre V, Barrueto L, et al. Effect of inhaled fluticasone on lung function in infants with recurrent wheezing: a randomised controlled trial. Allergol Immunopathol (Madr) 2009; 37: 57-62.

124 Pelkonen AS, Malmstrom K, Malmberg LP, et al. Budesonide improves decreased airway conductance in infants with respiratory symptoms. Arch Dis Child 2009; 94: 536-541.

125 Pelkonen AS, Malmstrom K, Sarna S, et al. The effect of montelukast on respiratory symptoms and lung function in wheezy infants. Eur Respir J 2013; 41: 664-670.

126 Palmer LJ, Rye PJ, Gibson NA, et al. Airway responsiveness in early infancy predicts asthma, lung function, and respiratory symptoms by school age. Am J Respir Crit Care Med 2001; 163: 37-42.

127 Malmstrom K, Pelkonen AS, Malmberg LP, et al. Lung function, airway remodelling and inflammation in symptomatic infants: outcome at 3 years. Thorax 2011; 66: 157-162.

128 Martinez FD, Morgan WJ, Wright AL, et al. Initial airway function is a risk factor for recurrent wheezing respiratory illnesses during the first three years of life. Group Health Medical Associates. Am Rev Respir Dis 1991; 143: 312-316.

129 Martinez FD, Morgan WJ, Wright AL, et al. Diminished lung function as a predisposing factor for wheezing respiratory illness in infants. $N$ Engl J Med 1988; 319: 1112-1117.

130 Murray CS, Pipis SD, McArdle EC, et al. Lung function at one month of age as a risk factor for infant respiratory symptoms in a high risk population. Thorax 2002; 57: 388-392.

131 Pike KC, Rose-Zerilli MJ, Osvald EC, et al. The relationship between infant lung function and the risk of wheeze in the preschool years. Pediatr Pulmonol 2011; 46: 75-82.

132 Cockcroft DW, Killian DN, Mellon JJ, et al. Bronchial reactivity to inhaled histamine: a method and clinical survey. Clin Allergy 1977; 7: 235-243.

133 Hargreave FE, Ryan G, Thomson NC, et al. Bronchial responsiveness to histamine or methacholine in asthma: measurement and clinical significance. J Allergy Clin Immunol 1981; 68: 347-355.

134 Aas K. Bronchial provocation tests in asthma. Arch Dis Child 1970; 45: 221-228.

135 Jones RS, Wharton MJ, Buston MH. The place of physical exercise and bronchodilator drugs in the assessment of the asthmatic child. Arch Dis Child 1963; 38: 539-545.

136 Zach MS, Polgar G. Cold air challenge of airway hyperreactivity in children: dose-response interrelation with a reaction plateau. J Allergy Clin Immunol 1987; 80: 9-17.

137 Rosenthal RR. Simplified eucapnic voluntary hyperventilation challenge. J Allergy Clin Immunol 1984; 73: 676-679.

138 Henriksen JM, Dahl R. Effects of inhaled budesonide alone and in combination with low-dose terbutaline in children with exercise-induced asthma. Am Rev Respir Dis 1983; 128: 993-997.

139 van Essen-Zandvliet EE, Hughes MD, Waalkens HJ, et al. Effects of 22 months of treatment with inhaled corticosteroids and/or beta-2-agonists on lung function, airway responsiveness, and symptoms in children with asthma. The Dutch Chronic Non-specific Lung Disease Study Group. Am Rev Respir Dis 1992; 146: $547-554$.

140 Nuijsink M, Hop WC, Sterk PJ, et al. Long-term asthma treatment guided by airway hyperresponsiveness in children: a randomised controlled trial. Eur Respir J 2007; 30: 457-466.

141 Riiser A, Hovland V, Carlsen KH, et al. Does bronchial hyperresponsiveness in childhood predict active asthma in adolescence? Am J Respir Crit Care Med 2012; 186: 493-500.

142 Piacentini GL, Bodini A, Costella S, et al. Exhaled nitric oxide and sputum eosinophil markers of inflammation in asthmatic children. Eur Respir J 1999; 13: 1386-1390. 
143 Lex C, Ferreira F, Zacharasiewicz A, et al. Airway eosinophilia in children with severe asthma - predictive values of noninvasive tests. Am J Respir Crit Care Med 2006; 174: 1286-1291.

144 Taylor DR, Pijnenburg MW, Smith AD, et al. Exhaled nitric oxide measurements: clinical application and interpretation. Thorax 2006; 61: 817-827.

145 Kaptein AA, Hughes BM, Scharloo M, et al. Illness perceptions about asthma are determinants of outcome. J Asthma 2008; 45: 459-464.

146 Dweik RA, Boggs PB, Erzurum SC, et al. An official ATS clinical practice guideline: interpretation of exhaled nitric oxide levels (FENO) for clinical applications. Am J Respir Crit Care Med 2011; 184: 602-615.

147 Smith AD, Cowan JO, Brassett KP, et al. Use of exhaled nitric oxide measurements to guide treatment in chronic asthma. N Engl J Med 2005; 352: 2163-2173.

148 Pijnenburg MW, Bakker EM, Hop WC, et al. Titrating steroids on exhaled nitric oxide in children with asthma: a randomized controlled trial. Am J Respir Crit Care Med 2005; 172: 831-836.

149 Fritsch M, Uxa S, Horak F, et al. Exhaled nitric oxide in the management of childhood asthma: a prospective 6-months study. Pediatr Pulmonol 2006; 41: 855-862.

150 Szefler SJ, Mitchell H, Sorkness CA, et al. Management of asthma based on exhaled nitric oxide in addition to guideline-based treatment for inner-city adolescents and young adults: a randomised controlled trial. Lancet 2008; 372: 1065-1072.

151 Singer F, Luchsinger I, Inci D, et al. Exhaled nitric oxide in symptomatic children at preschool age predicts later asthma. Allergy 2013; 68: 531-538.

152 Moeller A, Diefenbacher C, Lehmann A, et al. Exhaled nitric oxide distinguishes between subgroups of preschool children with respiratory symptoms. J Allergy Clin Immunol 2008; 121: 705-709.

153 Debley JS, Stamey DC, Cochrane ES, et al. Exhaled nitric oxide, lung function, and exacerbations in wheezy infants and toddlers. J Allergy Clin Immunol 2010; 125: 1228-1234.

154 Chawes BL, Buchvald F, Bischoff AL, et al. Elevated exhaled nitric oxide in high-risk neonates precedes transient early but not persistent wheeze. Am J Respir Crit Care Med 2010; 182: 138-142.

155 Petsky HL, Cates CJ, Li A, et al. Tailored interventions based on exhaled nitric oxide versus clinical symptoms for asthma in children and adults. Cochrane Database Syst Rev 2009; 4: CD006340.

156 Efthimiadis A, Jayaram L, Weston S, et al. Induced sputum: time from expectoration to processing. Eur Respir J 2002; 19: 706-708.

157 Lex C, Payne DN, Zacharasiewicz A, et al. Sputum induction in children with difficult asthma: safety, feasibility, and inflammatory cell pattern. Pediatr Pulmonol 2005; 39: 318-324.

158 Gibson PG. Sputum induction in children. Eur Respir J 2002; 20: Suppl. 37, 44s-46s.

159 Zacharasiewicz A, Wilson N, Lex C, et al. Clinical use of noninvasive measurements of airway inflammation in steroid reduction in children. Am J Respir Crit Care Med 2005; 171: 1077-1082.

160 Li AM, Tsang TW, Lam HS, et al. Predictors for failed dose reduction of inhaled corticosteroids in childhood asthma. Respirology 2008; 13: 400-407.

161 Fleming L, Tsartsali L, Wilson N, et al. Sputum inflammatory phenotypes are not stable in children with asthma. Thorax 2012; 67: 675-681.

162 Baraldi E, Ghiro L, Piovan V, et al. Safety and success of exhaled breath condensate collection in asthma. Arch Dis Child 2003; 88: 358-360.

163 Horvath I, Hunt J, Barnes PJ, et al. Exhaled breath condensate: methodological recommendations and unresolved questions. Eur Respir J 2005; 26: 523-548.

164 Klok T, Brand PL, Bomhof-Roordink H, et al. Parental illness perceptions and medication perceptions in childhood asthma, a focus group study. Acta Paediatr 2011; 100: 248-252.

165 Koster ES, Wijga AH, Koppelman GH, et al. Uncontrolled asthma at age 8: the importance of parental perception towards medication. Pediatr Allergy Immunol 2011; 22: 462-468.

166 Kaptein AA, Klok T, Moss-Morris R, et al. Illness perceptions: impact on self-management and control in asthma. Curr Opin Allergy Clin Immunol 2010; 10: 194-199.

167 Brouwer AF, Brand PL. Asthma education and monitoring: what has been shown to work. Paediatr Respir Rev 2008; 9: 193-199.

168 Kuethe MC, Vaessen-Verberne AA, Bindels PJ, et al. Children with asthma on inhaled corticosteroids managed in general practice or by hospital paediatricians: is there a difference? Prim Care Respir J 2010; 19: 62-67.

169 Jentzsch NS, Camargos P, Sarinho ES, et al. Adherence rate to beclomethasone dipropionate and the level of asthma control. Respir Med 2012; 106: 338-343.

170 Nikander K, Turpeinen M, Pelkonen AS, et al. True adherence with the Turbuhaler in young children with asthma. Arch Dis Child 2011; 96: 168-173.

171 Klok T, Kaptein AA, Duiverman EJ, et al. High inhaled corticosteroids adherence in childhood asthma: the role of medication beliefs. Eur Respir J 2012; 40: 1149-1155.

172 Lasmar L, Camargos P, Bousquet J, et al. Factors related to lower adherence rates to inhaled corticosteroids in children and adolescents: a prospective randomized cohort study. J Trop Pediatr 2009; 55: 20-25.

173 Spicher M, Bollers N, Chinn T, et al. Adherence in single-parent households in a long-term asthma clinical trial. Pediatr Nurs 2012; 38: 207-213.

174 Otsuki M, Eakin MN, Rand CS, et al. Adherence feedback to improve asthma outcomes among inner-city children: a randomized trial. Pediatrics 2009; 124: 1513-1521.

175 Bender BG, Bartlett SJ, Rand CS, et al. Impact of interview mode on accuracy of child and parent report of adherence with asthma-controller medication. Pediatrics 2007; 120: e471-e477.

176 Brand PL, Klok T, Kaptein AA. Using communication skills to improve adherence in children with chronic disease: the adherence equation. Paediatr Respir Rev 2013; 14: 219-223.

177 Kamps AW, van Ewijk B, Roorda RJ, et al. Poor inhalation technique, even after inhalation instructions, in children with asthma. Pediatr Pulmonol 2000; 29: 39-42.

178 Kamps AW, Brand PL, Roorda RJ. Determinants of correct inhalation technique in children attending a hospital-based asthma clinic. Acta Paediatr 2002; 91: 159-163.

179 Minai BA, Martin JE, Cohn RC. Results of a physician and respiratory therapist collaborative effort to improve long-term metered-dose inhaler technique in a pediatric asthma clinic. Respir Care 2004; 49: 600-605. 


\section{JMed 2012; 367: 904-912.}

186 Todd GR, Acerini CL, Ross-Russell R, et al. Survey of adrenal crisis associated with inhaled corticosteroids in the United Kingdom. Arch Dis Child 2002; 87: 457-461.

187 Zollner EW, Lombard CJ, Galal U, et al. Hypothalamic-pituitary-adrenal axis suppression in asthmatic school children. Pediatrics 2012; 130: e1512-e1519. corticosteroid use in asthma: collaboration of American College of Chest Physicians, American Academy of Allergy, Asthma, and Immunology, and American College of Allergy, Asthma, and Immunology. Chest 2003; 124: 2329-2340. 2008; 93: 644-645

Pedersen S. Do inhaled corticosteroids inhibit growth in children? Am I Respir Crit Care Med 2001; 164: 521-535.

Carlsen KH. Inhaled steroids and local side-effects. Allergy 2001; 56: 925-927.

de Groot EP, Duiverman EJ, Brand PL. Comorbidities of asthma during childhood: possibly important, yet poorly studied. Eur Respir J 2010; 36: 671-678.

Chawes BL, Bonnelykke K, Kreiner-Moller E, et al. Children with allergic and nonallergic rhinitis have a similar risk of asthma. J Allergy Clin Immunol 2010; 126: 567-573.

Kang HY, Park CS, Bang HR, et al. Effect of allergic rhinitis on the use and cost of health services by children with asthma. Yonsei Med J 2008; 49: 521-529.

Kiotseridis H, Cilio CM, Bjermer L, et al. Quality of life in children and adolescents with respiratory allergy, assessed with a generic and disease-specific instrument. Clin Respir J 2013; 7: 168-175.

Bergstrom SE, Boman G, Eriksson L, et al. Asthma mortality among Swedish children and young adults, a 10-year study. Respir Med 2008; 102: 1335-1341.

Chafen JJ, Newberry SJ, Riedl MA, et al. Diagnosing and managing common food allergies: a systematic review. JAMA 2010; 303: 1848-1856.

Nicolaou N, Poorafshar M, Murray C, et al. Allergy or tolerance in children sensitized to peanut: prevalence and differentiation using component-resolved diagnostics. J Allergy Clin Immunol 2010; 125: 191-197.

de Jong AB, Dikkeschei LD, Brand PL. Sensitization patterns to food and inhalant allergens in childhood: a comparison of non-sensitized, monosensitized, and polysensitized children. Pediatr Allergy Immunol 2011; 22: $166-171$.

Muraro A, Roberts G, Worm M, et al. Anaphylaxis: guidelines from the European Academy of Allergy and Clinical Immunology. Allergy 2014; 69: 1026-1045.

Blondeau K, Mertens V, Dupont L, et al. The relationship between gastroesophageal reflux and cough in children with chronic unexplained cough using combined impedance-pH-manometry recordings. Pediatr Pulmonol 2011; 46: $286-294$

Tolia V, Vandenplas Y. Systematic review: the extra-oesophageal symptoms of gastro-oesophageal reflux disease in children. Aliment Pharmacol Ther 2009; 29: 258-272.

Stordal K, Johannesdottir GB, Bentsen BS, et al. Acid suppression does not change respiratory symptoms in children with asthma and gastro-oesophageal reflux disease. Arch Dis Child 2005; 90: 956-960.

Writing Committee for the American Lung Association Asthma Clinical Research Centers, Holbrook JT, Wise $\mathrm{RA}$, Gold $\mathrm{BD}$, et al. Lansoprazole for children with poorly controlled asthma: a randomized controlled trial. JAMA 2012; 307: 373-381.

Cibella F, Cuttitta G, La Grutta S, et al. A cross-sectional study assessing the relationship between BMI, asthma, atopy, and eNO among schoolchildren. Ann Allergy Asthma Immunol 2011; 107: 330-336.

Corbo GM, Forastiere F, De Sario M, et al. Wheeze and asthma in children - associations with body mass index, sports, television viewing, and diet. Epidemiology 2008; 19: 747-755.

Forno E, Lescher R, Strunk R, et al. Decreased response to inhaled steroids in overweight and obese asthmatic children. J Allergy Clin Immunol 2011; 127: 741-749.

O'Byrne PM, Pedersen S, Schatz M, et al. The poorly explored impact of uncontrolled asthma. Chest 2013; 143: 511-523.

Schachter LM, Peat JK, Salome CM. Asthma and atopy in overweight children. Thorax 2003; 58: $1031-1035$.

Collins RA, Parsons F, Deverell M, et al. Risk factors for bronchial hyperresponsiveness in teenagers differ with sex and atopic status. J Allergy Clin Immunol 2011; 128: 301-307.

Kabir Z, Manning PJ, Holohan J, et al. Second-hand smoke exposure in cars and respiratory health effects in children. Eur Respir J 2009; 34: 629-633.

Vargas PA, Brenner B, Clark S, et al. Exposure to environmental tobacco smoke among children presenting to the emergency department with acute asthma: a multicenter study. Pediatr Pulmonol 2007; 42: 646-655.

Cook DG, Strachan DP. Summary of effects of parental smoking on the respiratory health of children and implications for research. Thorax 1999; 54: 357-365.

Chang MY, Hogan AD, Rakes GP, et al. Salivary cotinine levels in children presenting with wheezing to an emergency department. Pediatr Pulmonol 2000; 29: 257-263.

2 Gerald LB, Gerald JK, Gibson L, et al. Changes in environmental tobacco smoke exposure and asthma morbidity among urban school children. Chest 2009; 135: 911-916.

Wilson SR, Farber HJ, Knowles SB, et al. A randomized trial of parental behavioral counseling and cotinine feedback for lowering environmental tobacco smoke exposure in children with asthma: results of the LET'S Manage Asthma Trial. Chest 2011; 139: 581-590.

214 Priest N, Roseby R, Waters E, et al. Family and carer smoking control programmes for reducing children's exposure to environmental tobacco smoke. Cochrane Database Syst Rev 2008; 8: CD001746. 
215 Plopper CG, Fanucchi MV. Do urban environmental pollutants exacerbate childhood lung diseases? Environ Health Perspect 2000; 108: A252-A253.

216 Pinkerton KE, Joad JP. The mammalian respiratory system and critical windows of exposure for children's health. Environ Health Perspect 2000; 108: Suppl. 3, 457-462.

217 Kim JJ, American Academy of Pediatrics Committee on Environmental Health. Ambient air pollution: health hazards to children. Pediatrics 2004; 114: 1699-1707.

218 Dietert RR, Etzel RA, Chen D, et al. Workshop to identify critical windows of exposure for children's health: immune and respiratory systems work group summary. Environ Health Perspect 2000; 108: Suppl. 3, 483-490.

219 European Centre for Environment and Health. Effects of air pollution on children's health and development. A review of evidence. Special Programme on Health and Development. Denmark, European Centre for Environment and Health, 2005.

220 Gauderman WJ, Avol E, Gilliland F, et al. The effect of air pollution on lung development from 10 to 18 years of age. N Engl J Med 2004; 351: 1057-1067.

221 Morgan WJ, Crain EF, Gruchalla RS, et al. Results of a home-based environmental intervention among urban children with asthma. N Engl J Med 2004; 351: 1068-1080.

222 Gøtzsche PC, Johansen HK. House dust mite control measures for asthma. Cochrane Database Syst Rev 2008; 2: CD001187.

223 Platts-Mills TA. Allergen avoidance in the treatment of asthma: problems with the meta-analyses. J Allergy Clin Immunol 2008; 122: 694-696. 